\title{
Clinicopathological Profile of the von Willebrand Disease in a Tertiary Care Centre in Varanasi
}

\author{
Pawan K. Pandey ${ }^{1}$ Vijai Tilak ${ }^{1}$ Mahima Yadav $^{1}$ Neelu Kashyap ${ }^{1}$ \\ 1 Department of Pathology, Institute of Medical Sciences, Banaras \\ Hindu University, Varanasi, Uttar Pradesh, India \\ J Lab Physicians 2022;14:16-20.

\begin{abstract}
Address for correspondence Mahima Yadav, MD, Department of Pathology, Institute of Medical Sciences, Banaras Hindu University, D63/13 A, 6 Annapoorna Nagar, Mahmoorganj, Varanasi 221010, Uttar Pradesh, India (e-mail: mahima.yadav@gmail.com).
\end{abstract}

\begin{abstract}
Keywords

- von Willebrand disease

- subtypes

- RIPA
\end{abstract}

\section{Introduction}

The von Willebrand disease (vWD) was first described by Dr. Eric von Willebrand in 1926 in a 13-year-old female with severe menorrhagia and called it hereditary pseudohemophilia. ${ }^{1}$ The gene for this factor $(v W F)$ is located on the short arm of chromosome 12. It is synthesized by endothelial cells and megakaryocytes and has multiple posttranslational modifications. ${ }^{1}$ Many studies have described vWD as the most common inherited bleeding disorder, affecting approximately 0.1 to $1 \%$ of the total population, whereas symptomatic vWD affects only $0.01 \%$ of the population. ${ }^{1}$ vWD is among the most common inherited bleeding disorders in India. It is classified in multiple subtypes and needs complex laboratory tests for accurate diagnosis. The aim of this study is to estimate the prevalence of vWD in patients presenting with bleeding in a tertiary care center in Northeast India, as this region is historically underdeveloped and this center is one of very few centers providing tertiary care. The objectives include laboratory evaluation of all patients presenting with bleeding to estimate the prevalence of vWD subtypes and describe the clinicopathological features among subtypes. This study is among the first few studies from this region with an in-depth evaluation of bleeding disorders and the results are compared with other studies also.

The International Society of Thrombosis and Hemostasis (ISTH) divides VWD into three types. The clinical, genetic, and laboratory profiles vary according to subtypes of vWD. ${ }^{2}$ published online September 8, 2021
DOI https://doi.org/ 10.1055/s-0041-1734018. ISSN 0974-2727. (c) 2021. The Indian Association of Laboratory Physicians. All rights reserved.

This is an open access article published by Thieme under the terms of the Creative Commons Attribution-NonDerivative-NonCommercial-License, permitting copying and reproduction so long as the original work is given appropriate credit. Contents may not be used for commercial purposes, or adapted, remixed, transformed or built upon. (https://creativecommons.org/ licenses/by-nc-nd/4.0/)

Thieme Medical and Scientific Publishers Pvt. Ltd., A-12, 2nd Floor, Sector 2, Noida-201301 UP, India 
Type 1: partial quantitative deficiency.

Type 2: qualitative defects in vWF, subtypes include the following:

- 2A: selective decrease in large functional vWF multimers and decreased platelet adhesion.

- 2B: increase in platelet (gp1b)-vWF binding, causing depletion of large vWF multimers.

- 2M: decrease in vWF-dependent platelet adhesion, no reduction of large $\mathrm{VWF}$ multimers.

- $2 \mathrm{~N}$ : impaired binding of vWF to factor VIII (FVIII), lowering FVIII levels.

Type 3: complete quantitative deficiency of $\mathrm{vWF}$ and decreased FVIII.

Clinical features include bleeding from mucous membranes, skin, and menorrhagia. Muscle and joint bleeding occurs in severe disease mimicking the features of hemophilia. Bleeding is mostly mild to moderate in severity. ${ }^{3}$ No single test is sufficient for the diagnosis of vWD. Laboratory evaluation of vWD is done by compiling results of several tests. Initial evaluation must include complete blood count, platelet counts, prothrombin time (PT), and activated partial thromboplastin time (APTT). If these tests are normal or show isolated prolongation of APTT, vWD-specific tests are done. These include vWF antigen levels, Ristocetin cofactor activity assay (vWF:RCo), vWF:RCo/vWF:Ag ratio, FVIII coagulant assay (FVIII:C), vWF multimer analysis, low-dose ristocetin-induced platelet aggregation (LD RIPA), vWF-FVIII binding assay (vWF/FVIII:B), vWF-collagen binding assay (vWF:CB), vWF propeptide ratio (vWFpp)/vWF:Ag, the DDAVP challenge testing (DDAVP responsiveness), and lastly genotyping can be done for diagnosis. ${ }^{1}$

\section{Materials and Methods}

The study is a prospective study conducted from time period of January 2014 to December 2018. Inclusion criteria include all patients referred to pathology department with bleeding manifestations. Detailed clinical history was taken including age of onset, nature, amount and frequency of bleeding, family history, medication history, menstrual history in females, and blood loss during dental/surgical procedures.

Sodium citrate of $3.2 \%$ was used as anticoagulant for coagulation and platelet studies, in 1:9 ratios and processed within 4 hours. Complete blood count with platelet count was done.

Ethylenediamine tetraacetic acid (EDTA) samples were tested for a complete hemogram with platelet count. Platelet studies were done on platelet-rich plasma and coagulation studies were done on platelet poor plasma. Laboratory analysis for vWD comprised of tests like PT, APTT, FVIII:C, and these were performed manually. Bleeding time (BT) was done by modified Ivy's method. vWF:Ag was performed by enzyme-linked immunosorbent assay (ELISA; (Diagnostica Stago, France). RIPA by platelet aggregometry with ristocetin concentration of 1.5 $\mathrm{mg} / \mathrm{mL}$. LD RIPA at a concentration of $0.5 \mathrm{mg} / \mathrm{mL}$ (RIPA-LD). vWF CB (vWF:CB) was done by ELISA (Diagnostica Stago).
Table 1 Distribution of inherited bleeding disorders

\begin{tabular}{|l|l|l|}
\hline Diagnosis & No. & Percentage \\
\hline Hemophilia A & 151 & 63.7 \\
\hline Hemophilia B & 31 & 13.1 \\
\hline von Willebrand disease & 38 & 16.0 \\
\hline Platelet disorders & 10 & 4.2 \\
\hline Factor XIII & 5 & 2.1 \\
\hline Factor X & 1 & 0.4 \\
\hline Factor VII & 1 & 0.4 \\
\hline
\end{tabular}

\section{Results}

A total of 1,126 cases of bleeding manifestations were evaluated, and 237 cases were diagnosed as inherited bleeding disorders in a time period of 4 years. Hemophilia A was the most common inherited bleeding disorder, diagnosed in 151 patients (63.7\%), Hemophilia B in 31 patients (13\%). vWD was diagnosed in 38 (16\%) of these 237 cases. The distribution of these 237 cases is tabulated in -Table 1 .

vWD patients' age ranged from 8 months to 55 years, although more prevalent in younger age group (mean age: 15 years). Females predominate over males and male-to-female ratio is 1:5 (6 males and 32 females diagnosed as vWD). Family history was not consistently positive in vWD patients, possibly due to social stigma. History of blood transfusions was present in six patients. Out of the 38 diagnosed cases of vWD, 37 presented with spontaneous bleeding and one presented with excessive posttraumatic bleeding.

Type- $1 \mathrm{vWD}$ was the most frequent with 25 cases (65.7\%) followed by type $2 \mathrm{~N}$ with 7 cases $(18.4 \%)$. Only four cases were found to be of type 3 (10.5\%). Type $2 \mathrm{~B}$ was not seen. The distribution of the subtypes of VWD is shown in - Table 2 .

Distribution of clinical manifestations among subtypes was evaluated. Mucosal bleedings, such as epistaxis, menorrhagia, and gum bleeding, were frequently present and hemarthrosis was exceedingly rare, only presenting in one each of type 3 and type $2 \mathrm{~N}$, both classically associated with reduced FVIII. Type-3 vWD showed severe disease with clinical features of bleeding like epistaxis and menorrhagia in females in almost all patients.

Laboratory evaluation of vWD was done, screening tests showed normal PT in all patients and prolonged APTT in type

Table 2 von Willebrand (vWD) subtypes

\begin{tabular}{|l|l|l|}
\hline Subtype & No. of cases & Percentage \\
\hline VWD 1 & 25 & 65.7 \\
\hline VWD 3 & 4 & 10.5 \\
\hline VWD 2A & 1 & 2.6 \\
\hline vWD 2M & 1 & 2.6 \\
\hline vWD 2N & 7 & 18.4 \\
\hline
\end{tabular}


Table 3 Laboratory features of vWD: screening tests

\begin{tabular}{|l|l|l|l|}
\hline vWD & $\begin{array}{l}\text { PT (mean } \\
\text { in } \\
\text { second) }\end{array}$ & $\begin{array}{l}\text { APTT (mean } \\
\text { in } \\
\text { second) }\end{array}$ & BT (second) \\
\hline Control & $12.5-13.5$ & $26-30$ & $120-300$ \\
\hline 1 & 14.2 & 30.9 & 402 \\
\hline 3 & 14.4 & 62.9 & 915 \\
\hline $2 \mathrm{~A}$ & 14.8 & 26 & 525 \\
\hline $2 \mathrm{M}$ & 13.8 & 33.3 & 690 \\
\hline $2 \mathrm{~N}$ & 13.8 & 55.5 & 902 \\
\hline
\end{tabular}

Abbreviations: APTT, activated partial thromboplastin time; BT, bleeding time; PT, prothrombin time; vWD, von Willebrand.

3 (mean: 62.9 seconds) and type 2N (mean: 55.5 seconds). The mean values are shown in - Table 3. Platelet count was adequate in all these cases, thus excluding any plateletrelated deficiency. Although type $2 \mathrm{~B}$ and pseudo-vWD show mild thrombocytopenia, we did not identify any of these two cases in our study. The diagnostic or confirmatory tests were done as tabulated in - Table $\mathbf{4}$ and $\mathbf{5}$.

FVIII:C-level evaluation was done and it was reduced in severe disease such as type 3 . When normal, it also helps in excluding the diagnosis of hemophilia A which has overlapping presentation. Since multimer study was not performed for subtyping, FVIII assay helped in diagnosing type $2 \mathrm{~N}$ which showed reduced FVIII and reduced FVIII binding.

FVIII binding (VIII B) is evaluated to diagnose type $2 \mathrm{~N}$ which shows disproportionately reduced FVIII binding (less than or equal to 20\%; Diagnostica Stago). Present study shows FVIII B value of $16 \%$ in type $2 \mathrm{~N}$. Also, it is extremely reduced in type- 3 vWD.

vWF:Ag level refers to quantitative estimation of vWF:Ag and were extremely low in type-3 vWD. However, some type- 1 and type-2 subtypes showed normal or near-normal values. To avoid missing these cases vWF:Ag levels should not be the sole determinant of vWD, and few functional assays were also included in the evaluation.

The vWF:CB is a more vWD-specific assay and gives estimate about the vWF function. The most functional multimers are high molecular weight multimers (HMWM) which

Table 4 Laboratory features of vWD used for diagnosis of subtypes

\begin{tabular}{|l|l|l|l|l|l|l|l|l|}
\hline vWD & FVIII & vWF:Ag & $\begin{array}{l}\text { vWFI } \\
\text { F VIIIB }\end{array}$ & vWF:CB & RIPA & LD RIPA & CB/Ag & $\begin{array}{l}\text { Multimer } \\
\text { analysis }\end{array}$ \\
\hline 1 & Low/normal & Low & Normal & Low & Normal/low & Low & Normal & All low \\
\hline 3 & Very low & Not measurable & Not used & Very low & Absent & Absent & Not used & Absent \\
\hline 2A & Normal/mild low & Mildly low & Normal & Very low & Normal/low & Absent & Low & $\begin{array}{l}\text { Absence of } \\
\text { large and } \\
\text { intermediate }\end{array}$ \\
\hline 2B & Normal/mild low & Normal/mild low & Normal & Low & Increased & Increased & Low & $\begin{array}{l}\text { Absence of } \\
\text { large }\end{array}$ \\
\hline 2M & Normal/mild low & Low & Normal & Low & Normal/low & Absent & Low/ normal & Normal \\
\hline 2N & Low & Normal & Low & Normal & Normal & Absent & Normal & Normal \\
\hline
\end{tabular}

Abbreviations: Ag, antigen; CB, collagen binding; FVIII, factor VIII; LD, low dose; RIPA, ristocetin-induced platelet aggregation; vWD, von Willebrand.

Table 5 Laboratory features of vWD (diagnostic tests): results

\begin{tabular}{|l|l|l|l|l|l|l|l|}
\hline vWD & $\begin{array}{l}\text { FVIII:C } \\
\text { (mean in \%) }\end{array}$ & $\begin{array}{l}\text { vWF:Ag } \\
\text { (mean in \%) }\end{array}$ & $\begin{array}{l}\text { vWF/FVIIIB } \\
\text { (mean in \%) }\end{array}$ & $\begin{array}{l}\text { vWF:CB } \\
\text { (mean in \%) }\end{array}$ & RIPA (mean) & LD RIPA (mean) & $\begin{array}{l}\text { CB/AG } \\
\text { (mean in \%) }\end{array}$ \\
\hline $\begin{array}{l}\text { Normal } \\
\text { range }\end{array}$ & $50-150$ & $70-150$ & $60-160$ & $64-160$ & $11.5-17$ seconds & $28-34$ seconds & $0.8-1.2$ \\
\hline 1 & $84-163(111)$ & $50-70(61.2)$ & $87-149(116)$ & $56-63(60)$ & $12.2-28.5(15.2)$ & $90-120(117.6)$ & Normal \\
\hline 3 & Undetectable & $3-6(5.0)$ & $5-8(6.5)$ & $1-3(2.2)$ & $>2$ minutes & $>2$ minutes & $\begin{array}{l}\text { Not } \\
\text { detectable }\end{array}$ \\
\hline $2 \mathrm{~A}$ & 60 & 48 & 106 & 30 & 26.2 & $>2$ minutes & $\begin{array}{l}\text { Reduced } \\
(0.6)\end{array}$ \\
\hline $2 \mathrm{M}$ & 76 & 35 & 108 & 51 & 29.3 & $>2$ minutes & Normal \\
\hline $2 \mathrm{~N}$ & $3-25(8.3)$ & $9-36(17.2)$ & $14-18(16)$ & $70-89(80)$ & $13.4-17(14.6)$ & $>2$ minutes & Normal \\
\hline
\end{tabular}

Abbreviations: Ag, antigen; C, coagulant; CB, collagen binding; FVIII, factor VIII; LD, low dose; RIPA, ristocetin-induced platelet aggregation; vWD, von Willebrand.

Note: All values are mean values, reference ranges are the laboratory reference ranges. 
are absent in subtypes $2 \mathrm{~A}$ and $2 \mathrm{~B}$, thus resulting in extremely low vWF:CB in these subtypes. In the present study, values of $\mathrm{vWF}$ :CB were the lowest in type 3 and, among type 2, the lowest in $2 \mathrm{~A}$, slightly low in $2 \mathrm{M}$, and normal in $2 \mathrm{~N}$.

vWF:CB/AG gives an estimate about qualitative defect versus quantitative defect as $C B$ is a functional assay and is reduced in absence of HMWM (subtypes $2 \mathrm{~A}, 2 \mathrm{~B}$ ), whereas vWF:Ag is a quantitative assay. If all the results of quantity and function are uniformly low, then the probability of quantitative deficiency like type 1 or 3 is considered. If the results are not uniformly low and functional assays, like $C B$, are reduced disproportionately to $\mathrm{Ag}$ levels, the ratio of $\mathrm{CB} / \mathrm{AG}$ is reduced. As in the present study, it is reduced in type $2 \mathrm{~A}$ allowing differentiation from quantitative defects like types 1 and 3. Also type 2A (loss of HMWM, so reduced $\mathrm{CB} / \mathrm{AG}$ ratio) can be differentiated from $2 \mathrm{M}$ (normal ratio) by this ratio in absence of multimer analysis.

Ristocetin-induced platelet aggregation: this test depends on function and number of vWF and normally aggregation will occur at ristocetin concentration of $1 \mathrm{mg} / \mathrm{mL}$ and above. Quantitative and qualitative defects will show reduced aggregation at $1 \mathrm{mg} / \mathrm{mL}$, whereas type $2 \mathrm{~B}$ shows increased sensitivity to LD ristocetin.

\section{Discussion}

vWD is one of the most common inherited bleeding disorder, although its incidence among patients referred at our center was second only to hemophilia A. In the present study, $16 \%$ of the referred patients were found to have vWD. In another Indian study by Ghosh et al, 81 patients out of 761 evaluated were found to have vWD (10.6\%). ${ }^{4}$ A previous study at our center of previous 4 years' identified vWD in 40 (17\%) out of 230 patients of inherited bleeding disorders. ${ }^{5}$ The prevalence of vWD in our region of eastern Uttar Pradesh, India, and adjoining states seems to be consistent as seen by the present study and previous study at the same center but of different periods and patients. - Table 6 compares the studies on vWD, and the percentage of vWD among inherited bleeding disorder ranges from 8.6 to $28.6 \%$ in these studies. The ratio of vWD to hemophilia A ranges from 0.1 to 0.23 in published Indian studies. ${ }^{4,6}$ The present study showed ratio of vWD to hemophilia A of 0.25 which is consistent with other published data.

Type- 1 vWD was the most frequent with 25 cases (65.7\%) followed by type $2 \mathrm{~N}$ with 7 cases (18.4\%). Only four cases were found to be of type 3 (10.5\%). This contrasts with other studies from Indian literature, whereas the western literature also states type- 1 as the most common subtype of vWD. Indian studies have possibly reported lower prevalence of type- $1 \mathrm{vWD}$ due to lower health awareness and ignorance of mild disease. However, study done by Gupta et al describes type 2 to be most common and describes possible misclassification of type 2 as type 1 in the absence of functional assays and multimer analysis. ${ }^{7,8}$

Majority of patients in the present study were females and the most common symptom was menorrhagia, similar to few other studies which stresses the importance of testing for inherited bleeding disorders in patients of menorrhagia. ${ }^{4,5}$ Platelet-type bleeding from mucous membranes was seen predominantly while only one case of hemarthrosis was seen in a type- $3 \mathrm{vWD}$ patient due to concurrent low FVIII levels in type 3.

Laboratory evaluation was performed including screening tests like PT, APTT, and BT and advanced diagnostic tests, such as vWF:Ag assay, FVIII:C assay, functional assays like RIPA, LDRIPA, $\mathrm{vWF}: \mathrm{CB}$, and $\mathrm{vWF} / \mathrm{FVIII}$ binding assay, were performed for diagnosis and subtyping. Levels were compared with the diagnostic criteria and categories defined. However multimer analysis and genetic studies were not performed. Another recent advance in the continuously evolving laboratory techniques is the vWF:GPIbM (recombinant/mutant glycoprotein) assay. This test eliminates need of ristocetin by introducing gain-of-function mutations in GPIb $\alpha$ receptor, so that it can spontaneously bind to vWF without ristocetin and has been reported to be more accurate; however, the availability of this test is very limited and not yet performed in India. ${ }^{9}$

Another recent study has proposed cutoff value less than $30 \mathrm{IU} / \mathrm{dL}$ for diagnosis of vWD, as it is associated with bleeding and mutations. ${ }^{9}$ But levels greater than 30 labeled as low vWF, presenting with abnormal bleeding that should be investigated for vWD type 1 . Type- 2 vWD can present with near-normal Ag levels, so functional assays will be needed for diagnosis. Also, genotyping has an important

Table 6 Distribution of von Willebrand (vWD) and its subtypes in published studies

\begin{tabular}{|l|l|l|l|l|l|l|l|l|}
\hline Study (year) & $\begin{array}{l}\text { No. of } \\
\text { patients }\end{array}$ & $\begin{array}{l}\text { No. of vWD } \\
\text { patients (\%) }\end{array}$ & Type 1 (\%) & Type 2A (\%) & $\begin{array}{l}\text { Type } \\
\text { 2B (\%) }\end{array}$ & $\begin{array}{l}\text { Type } \\
\text { 2M (\%) }\end{array}$ & $\begin{array}{l}\text { Type } \\
\text { 2N (\%) }\end{array}$ & Type 3 (\%) \\
\hline Gupta et al (2005) & 224 & $64(28.6)$ & $14(21.9)$ & $24(37.5)$ & - & $4(6)$ & - & $21(32.8)$ \\
\hline Trasi et al $(2005)^{11}$ & 796 & $58(7.3)$ & $18 \%$ & $9.5 \%$ & $4.7 \%$ & $1.2 \%$ & $3.6 \%$ & $59.5 \%$ \\
\hline Gupta et al $(2007)^{8}$ & 872 & $94(16.8)$ & $20(21.3)$ & $38(40.4)$ & - & $04(4.3)$ & - & $32(34.04)$ \\
\hline Ahmad et al $(2008)^{6}$ & 1,576 & $136(8.6)$ & $29(21.3)$ & - & - & - & - & $33(24.3)$ \\
\hline Kumar et al (2010) & 230 & $40(17.34)$ & $17(42.5)$ & $10(25)$ & - & - & $1(2.5)$ & $12(30.0)$ \\
\hline $\begin{array}{l}\text { Srivastava and } \\
\text { Rodeghiero }(2005)^{12}\end{array}$ & $200 \times 10^{6}$ & $\begin{array}{l}211 \\
(0.00001)\end{array}$ & - & - & - & & & $95(51.9)$ \\
\hline Present study & 237 & $38(16)$ & $25(65.7)$ & $1(2.6)$ & - & $1(2.6)$ & $7(18.4)$ & $4(10.5)$ \\
\hline
\end{tabular}


role in diagnosis of type $2 \mathrm{~N}^{2}$ Another important point is to make sure that repeat testing is always done for confirming the results. ${ }^{10-12}$

\section{Conclusion}

vWD is among the most common inherited bleeding disorders in the country second only to hemophilia A but due to the complex phenotype of disease and necessity of advanced tests and trained personnel, the diagnosis is sometimes difficult. This is especially true for India where majority of hematology laboratories do not have these facilities. The current study is one of the very few Indian studies that estimate the prevalence of vWD and describes the clinical and laboratory features including the advanced diagnostic tests. Treatment of vWD includes desmopressin, cryoprecipitate, plasma derived or recombinant vWF concentrates, and antifibrinolytics.

Ethics

This study was approved by institutional ethics committee.

\section{Conflict of Interest}

None declared.

\section{References}

1 Swami A, Kaur V. von Willebrand disease: a concise review and update for the practicing physician. Clin Appl Thromb Hemost 2017;23(08):900-910

2 Sadler JE, Budde U, Eikenboom JC, et al; Working Party on von Willebrand Disease Classification. Update on the pathophysiology and classification of von Willebrand disease: a report of the Subcommittee on von Willebrand Factor. J Thromb Haemost 2006;4(10):2103-2114

3 Yawn B, Nichols WL, Rick ME. Diagnosis and management of von Willebrand disease: guidelines for primary care. Am Fam Physician 2009;80(11):1261-1268

4 Ghosh K, Shetty S. Epidemiology, diagnosis, and management of von Willebrand disease in India. Semin Thromb Hemost 2011;37 (05):595-601

5 Kumar S, Kishore R, Gupta V, Jain M, Shukla J. Prevalence and spectrum of von Willebrand disease in Eastern Uttar Pradesh. Indian J Pathol Microbiol 2010;53(03):486-489

6 Ahmad F, Kannan M, Ranjan R, Bajaj J, Choudhary VP, Saxena R. Inherited platelet function disorders versus other inherited bleeding disorders: an Indian overview. Thromb Res 2008;121 (06):835-841

7 Gupta PK, Ahmed RP, Sazawal S, Choudhry VP, Saxena R. Relatively high frequency of VWD types 3 and 2 in a cohort of Indian patients: the role of multimeric analysis. J Thromb Haemost 2005;3(06):1321-1322

8 Gupta PK, Charan VD, Saxena R. Spectrum of Von Willebrand disease and inherited platelet function disorders amongst Indian bleeders. Ann Hematol 2007;86(06):403-407

9 Sharma R, Flood VH. Advances in the diagnosis and treatment of Von Willebrand disease. Blood 2017;130(22):2386-2391

10 Favaloro EJ. Appropriate laboratory assessment as a critical facet in the proper diagnosis and classification of von Willebrand disorder. Best Pract Res Clin Haematol 2001;14(02): 299-319

11 Trasi S, Shetty S, Ghosh K, Mohanty D. Prevalence and spectrum of von Willebrand disease from western India. Indian J Med Res 2005;121(05):653-658

12 Srivastava A, Rodeghiero F. Epidemiology of von Willebrand disease in developing countries. Semin Thromb Hemost 2005; 31(05):569-576 